\title{
Implementation of Gamification in Heis in the Republic of Macedonia
}

\author{
Martin Kiselicki $^{{ }^{*}}$ | Saso Josimovski \\ 1 Integrated Business Faculty, Skopje, Macedonia \\ 2 Faculty of Economics - Skopje, University „SS Cyril and Methodius“, Skopje, Macedonia
}

\begin{abstract}
The focus of the paper is gamification, which has been researched typically through its' implementation in the business sector. Our research follows the implementation of gamification in Higher Educational Institutions, since the same concepts and benefits that function in the workplace, should function with similar effect or yield even better results with students. The topic of gamification in education is a relatively novel one, with only a few papers addressing it in detail, especially on the Balkan region. The contribution of the paper is two-sided, i.e., through primary and secondary research, recommendations for optimal ways of implementing gamified systems in higher education is given, and according to the obtained data, present statistics and implications for implementing gamification in HEIs in the Republic of Macedonia. The core elements and mechanics of gamification are researched and adjusted in the context of education, as well as improving existing implementations of gamification in HEIs through the introduction of cycles of interest (rewards for encouraging a certain type of behavior of students) and cycles of progression (a stepwise increase in the weight of the activities).

The results of the primary research demonstrate that the concept of gamification offers great potential advantages for students and teaching staff, primarily by increasing the level of intrinsic motivation and the degree of completion of subjects. The paper uncovers the gamification mechanics and elements that would work best for HEIs in Macedonia, as well as outline the biggest motivational problems students have when navigating through the educational process. Through the primary research conducted, the first public available information on the introduction of gamification in higher education in the Republic of Macedonia is made available.
\end{abstract}

Key words: Gamification, Higher Education, Intrinsic motivation, Extrinsic Motivation, Motivators, Barriers

JEL Classification: I21, I23

\section{INTRODUCTION}

Gamification as a concept has been explored mainly in the business sector, to motivate employees outside of the traditional reward systems. Gamification is the use of elements, mechanics and way of thinking from video games in an environment that has no connections with video games (Detering, 2011; Van Der Boer, 2011). Since the introduction of the term in modern day business in 2008, gamification has been the focus of companies and researchers, due to the potential it offers regarding the motivation of employees, without depending on a financial reward system. Gamification exploits video game elements and mechanics to connect with employees on a deeper level, transforming work tasks to be more interactive and fun. The authors have already

\footnotetext{
*Corresponding Author, e-mail: artin.kiselicki@fbe.edu.mk
} 
researched the concept and its implementation in SMEs in Macedonia, and this paper represents a continuation of the research in the higher education sector. The main goal of gamification is to increase participant/employee motivation, which can be either intrinsic or extrinsic motivation (Benabou \& Tirole, 2003). Extrinsic motivation comes from external sources, such as financial rewards (such as salary increase, bonuses), recognition, future promotions etc. Intrinsic motivation is defined as coming from the individual himself, meaning he is not motivated by any specific rewards system, but instead get enjoyment from performing the task itself. The main objective of the paper is to research the current state of gamification in HEIs in the Republic of Macedonia, as well as analyze the potential for implementing it in the future.

\section{Methodology}

The paper examines the correlation between the implementation of gamification in higher education and the increase in students' motivation in HEIs to participate and complete activities related to the subjects/courses they enroll, through primary and secondary research. Additional focus is provided on researching the prerequisites for introducing gamification in education through secondary data. Student motivation is analyzed through secondary research, which covers the available data by analyzing the types of motivation (intrinsic and extrinsic), as well as methods for increasing it, while the primary research is conducted through a questionnaire on students from HEIs on the territory of the Republic of Macedonia. The questionnaire is composed of both open and closed questions, to better examine and understand various aspects of gamification and motivational techniques, as well as to give accurate predictions for implementation of gamified systems in HEIs.

\section{LITERATURE REVIEW}

The authors' previous research shows that video games, as a medium, are attractive because they generate intrinsic motivation. Gamers continue to perform trivial tasks because of the mechanics set up in the video game, and the inclusion of these types of mechanics in the workplace can create intrinsic motivation in employees (Kiselicki et al., 2018). According to Ryan and Deci (2000), there are five specific intrinsic motivators: Autonomy, Skills, Purpose, Progress and Social Interaction. Recent statistics show that there are more than 2.5 billion gamers ${ }^{1}$, while men and women are almost equally represented (59\% male and $41 \%$ female $)^{2}$. The largest percentage of gamers are between the ages of 21-35 (35\%), which is an age group current students are mostly a part of. The second largest groups is 10-20 year olds (22\%), which represent current and future students $^{3}$. There are specific models (Yousef Adel et al., 2011) concerned with the learning divide and providing educational services in digital form (e-learning), which can increase the reach of HEIs, as well as provide as basis for implementing gamification. Since current and future higher education students are composed of the so-called "Generation Z", there could be great benefits in introducing the concept of gamification in the classroom. Generations born between 1995 and 2014 with immediate contact with new technology such as the Internet, cellphones/smartphones and digital media are considered a part of Generation Z (Singh \& Dangmei, 2016). This generation has been born and raised in a digital world, including access to video games at a very young age, so they are well aware of the mechanics and elements of video games, meaning that implementing a gamification system in their educational process can be easily recognized and connected with.

According to statistics in the United States and the EU, only 56\% of students complete their four-year studies within the predicted six-year period, indicating that there could be some

\footnotetext{
${ }^{1}$ https://www.wepc.com/news/video-game-statistics/

${ }^{2}$ https://www.bigfishgames.com/blog/2017-video-game-trends-and-statistics-whos-playing-what-andwhy/

${ }^{3}$ https://www.statista.com/statistics/722259/world-gamers-by-age-and-gender/
} 
systematic shortcomings in the design of the educational process itself (Symonds et al., 2011). It is evident that once students go out of the loop and start being late with exams, it begins a downward spiral that could result in finishing their studies late (7-10 years) or even not graduating at all. The rationality behind the benefits of gamifying the study process in HEIs is the creation of higher levels of interaction, immersion and motivation among students when participating in activities during and outside the classroom. The use of game mechanics can boost learning skills by $40 \%$, leading to higher level of commitment and task completion (Kiryakova et al., 2014).

\section{Difference with Game-based Learning}

The closest implementations of gamification in the classroom are Game-based Learning (GBL) initiatives. GBL is defined as the type of gameplay with defined learning outcomes, with the objective being to prioritize gameplay to cover the subject matter (Plass et al., 2015). GBL initiatives could include digital games (such as "Call of Duty: World at War") to introduce concepts around World War II, with the goal being to interest students in identifying historically accurate events and areas. Another example would be to utilize a driving game to challenge students to text and drive, with the goal being to measure reaction time, speed and other variables. Utilizing video game hardware is also part of GBL, such as Microsoft "Xbox Kinect" and specific compatible video games in Physical Education classes and sports training to engage students in an active way (Hill E., 2015).

Although this over lapses with concepts of implanting gamification in education (such as including digital games), it is not the same as a gamified educational system. Gamification is not the inclusion of an entire video game in the learning process, instead focusing on the mechanics implemented in various video games which motivate players to continue performing tasks and playing. These mechanics can include virtual experience points, player levels, player badges earned through performing specific tasks, leader boards and ranking systems, specific skills earned through performing tasks etc. In the context of the example with "Call of Duty", a gamified system would implement certain elements of the video game, such as mimicking the progression system and connecting it with specific class-related tasks, giving players (students) the ability to earn new skills based on their class performance and having a daily/weekly/monthly leader board system that is easily viewable for everyone. These are certain mechanics which motivate players to come back to the specific video game and therefore have the potential to create intrinsic motivation in students as well.

\section{Existing research on Gamification in Higher Education}

Lee Sheldon (2012) has documented one of the first successful implementations of gamification in education. In 2009, he began modeling his course as a Massively Multiplayer Online Role Playing Game (MMORPG), transforming class activities in the process. Students created their own avatars, they formed guilds (an alternative term to groups in MMORPG) and they completed tasks/quests to gain experience points and gain new levels. If the student reached level 12 by the end of the semester, they would receive an A. The average student grade was improved from "C" to "B" (in ECTS system of evaluation), while also attendance records rose drastically. Gamification in education in recent years has been increasingly implemented through digitalization and smartphone applications as well. For example, if teachers want to implement gamification in a simple manner, they can utilize applications such as Superfunner, which gives students experience points, badges and levels for various classroom activities (Nicholson, 2013). 


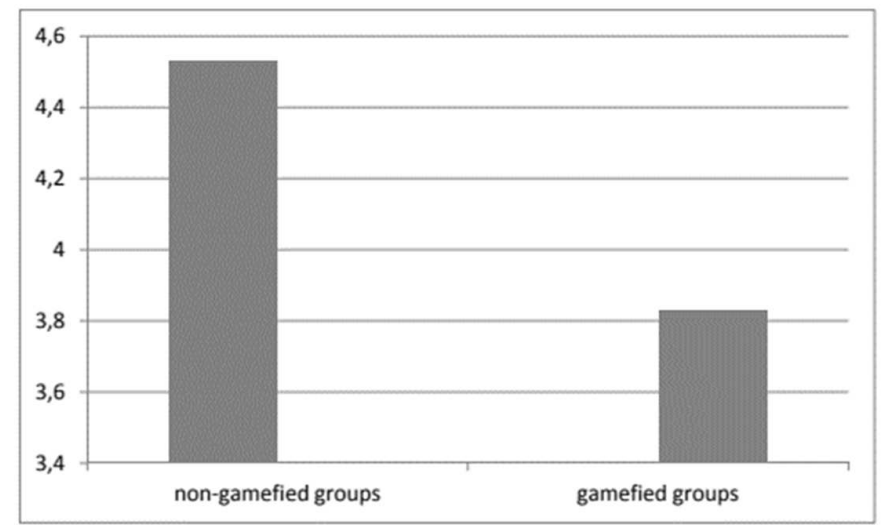

Graph 1. Average grade for students

Source: Laskowski M., Badurowicz M., 2014

Graph 1 demonstrates the results of the classroom experiments on gamification from Laskowski and Badurowicz (2014). They performed testing on 62 students from Master Studies and divided them into two groups, with one being given a gamified learning experience. Their research shows that students from the gamified group had an average grade of 4.5 , while students from the non-gamified group had an average grade of 3.8. Gamified groups also had higher attendance records over regular students and higher homework completion rate.

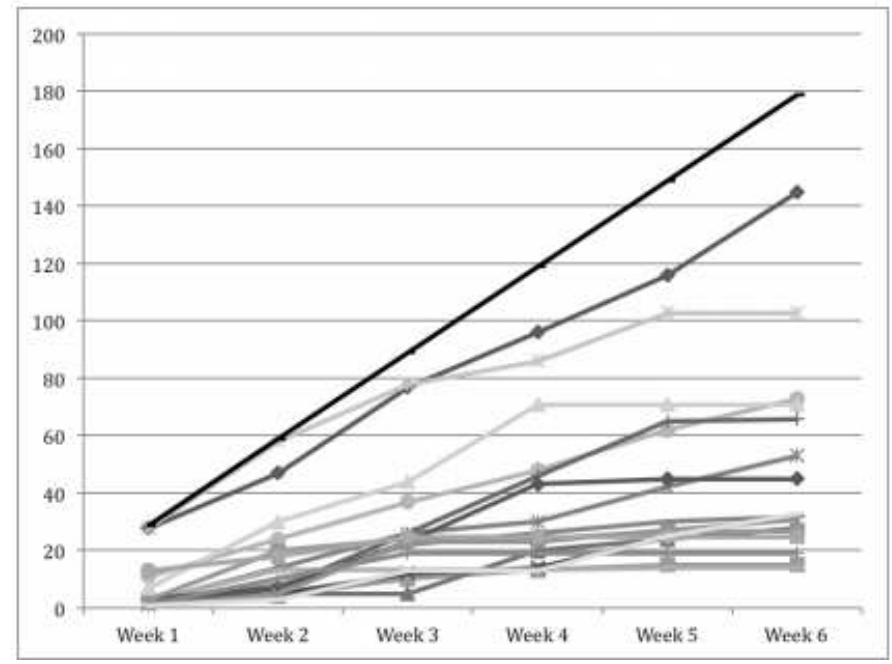

Graph 2. Student engagement levels

Source: Nicholson, S., 2013

Graph 2 shows the participation of students in classes via the application Superfunner, performed on two courses by Scott Nicholson (2013). After the initial positive reactions and involvement by students in weeks 1 through 3, participation fell through in latter weeks (4-6). This means that gamification has to be implemented in courses in a meaningful and consistent way, as well as ensure that points and activities are spread equally throughout the semester to ensure constant student involvement and interaction. Another problem that appeared was students being demotivated if they fall behind classmates, especially on the leaderboard rankings. Their demotivation was even higher knowing that there is no way to catch up in the following 
weeks to the leader, making them feel that it is futile to even attempt it and ultimately becoming disinterested in class.

An interesting take on gamification can be found in the work of Nina Frischmann (2014), who designed her course as a fantasy multiplayer game, where students create their own avatars and join guilds in the continent of "Educopia". The players (students) begin with zero experience points (just as in role-playing video games) and they gain experience points by performing various tasks (named quests) and other specific actions. By acquiring experience points, players level up (with 9 levels in total), where each level bring specific skills to the player, for example "skip 1 tasks and still get experience points" or "add 15 experience points to any assignment". The final level gives the player the ultimate skill - earn an " $\mathrm{A}$ " in the course. In terms of gamification, this is the most accurate implementation of the process and has the potential to make classroom tasks and homework entertaining by themselves. One of the problems faced in this particular implementation was the lack of real-time feedback, because students can only view their level and progress while in class and when they request it from the teacher.

\section{System for implementing gamification in the educational process}

There are various implementations of gamification in education, each bringing its own set of benefits and drawbacks. In our previous research for implementing gamification systems in the workplace, we concluded that it is paramount to follow specific steps when gamifying tasks, which can also hold true in education. Gamification is implemented in the educational sector through a system of elements, mechanisms and rewards and the four steps should also be followed in the educational sector as well (Aparicio, 2012):

1. Identification of the main tasks - the classroom tasks that needs to be gamified

2. Identification of transversal objectives - other objectives besides the main objective that would be interesting and attractive for students to perform the activity

3. Selection of gamification mechanisms - depending on the main goal, related to the elements of intrinsic motivation

4. Analysis and control - through tests with specific metrics, questionnaires, or evaluation of experts on gamified processes and mechanisms applied, in order to compare the results before and after implementing gamification in activities

Another important aspect seen in previous attempts at implementing gamification in courses is students becoming disinterested in latter weeks, either because they are well behind class-mates or because tasks and rewards are repetitive. To minimize these types of problems, the system should be evaluated in two aspects:

1. Cycles of interest - important for encouraging students to engage in the initial phase and start performing tasks, by following a three-step infrastructure: 1.Motivation; 2. Action 3. Feedback

2. Progression cycles - important to ensure that earlier levels in the beginning are easy enough for players to get engaged, while later levels from the gamified system are challenging enough for players to continue be engaged.

Gamified systems in education should also include four different dynamics to boost learning and engage students (Stott \& Neustaedter, 2013):

1. Freedom to fail - game design should encourage students to experiment without fear, by giving them multiple chances to tackle a certain task

2. Rapid feedback - students should get real-time and continuous feedback whenever possible, such as visual cues or a progression bar 
3. Progression - gamified courses should include the most interesting elements at the beginning, to gain the attention of students. However, the difficulty should be increased as the course progresses, to maintain student interest throughout the semester

4. Storytelling - since most games include some type of story, gamified courses should be no different. Including a story can be an enticing experience for the students and should increase their engagement and motivation levels.

\section{RESEARCH}

The primary research for this paper is done through a questionnaire (structured of 11 questions, 10 closed questions and 1 open-ended question). The survey was conducted on students from public and private HEIs in the Republic of Macedonia. Since there were no further restrictions on demographic characteristics or type of studies, students were selected at random, with the questionnaire being sent to them in a digital form, through the digital platform Google Docs. Students were also encouraged to share the questionnaire with their peers, in an effort to get a larger sample. A total of 238 responses were received in the period of 03.05.2018 through 10.10.2018, of which 18 of them were ruled as invalid or incomplete, leaving 220 valid responses. The questionnaire in its original form is contained in the annex of the paper. Through extensive inquiry on student motivation, class satisfaction and connection with video games/mobile games, we can evaluate the potential for implementing gamification in the curriculums of HEIs in the Republic of Macedonia. Most of the students are enrolled social sciences (44\%), followed by natural sciences (29\%), applied sciences (16\%) and humanities and arts (11\%). From the respondents, $66.4 \%$ are male students, while $33.6 \%$ are female students.

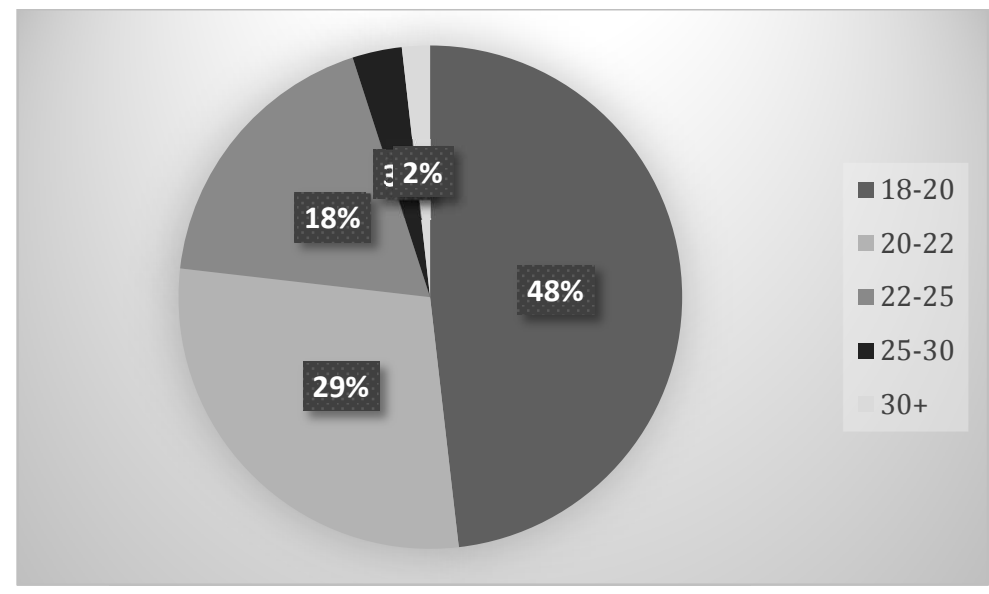

Graph 3. Student age distribution

Source: Own researh

Graph 3 shows the age distribution between respondents. The most prominent group are students aged between 18-20, followed by 20-22 year olds and 22-25 year old, which comprise $95 \%$ of all respondents. 


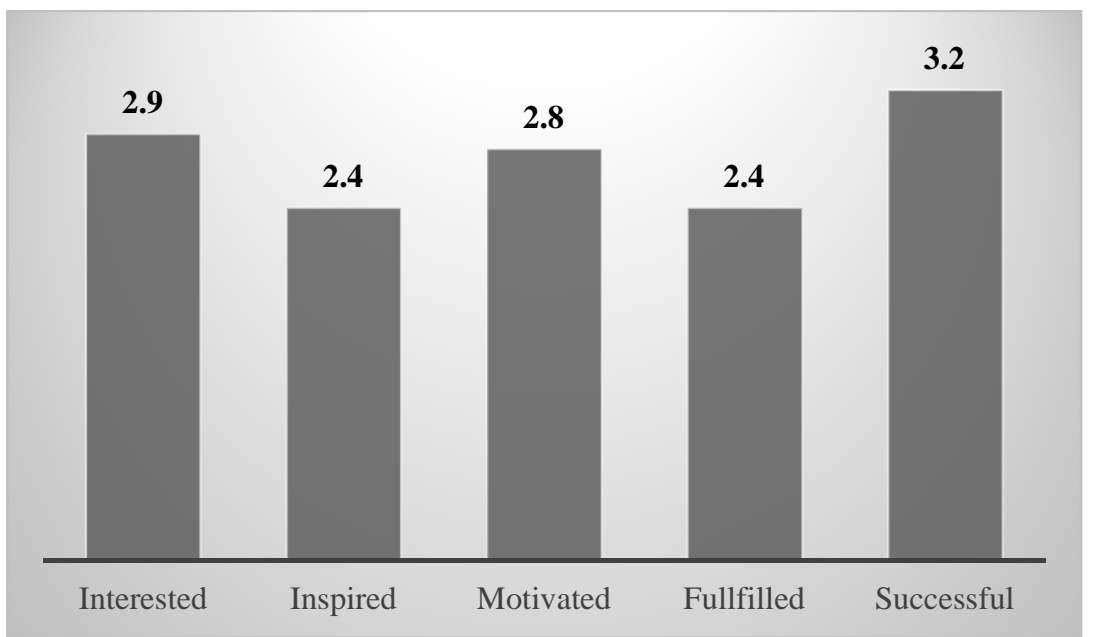

Graph 4. Student view towards classes

Source: Own source

Graph 4 demonstrates students' feelings during classes. Since gamification focuses on intrinsic motivation, it is important to understand whether students are currently engaged in classes and draw positive feelings towards their respective faculties. The answers were based on a 5-point Likert scale, with 1 being the lowest and 5 being the highest grade. Students' answers were averaged, where the best average grade was students feeling successful in their studies with 3.2 (out of 5), followed by being interested in classes (2.8 out of 5) and motivated (2.8 out of 5). Generally, average grades are low, most of them being below an average grade of 3 , thus there could be potential for gamification to be introduced and yield positive results.

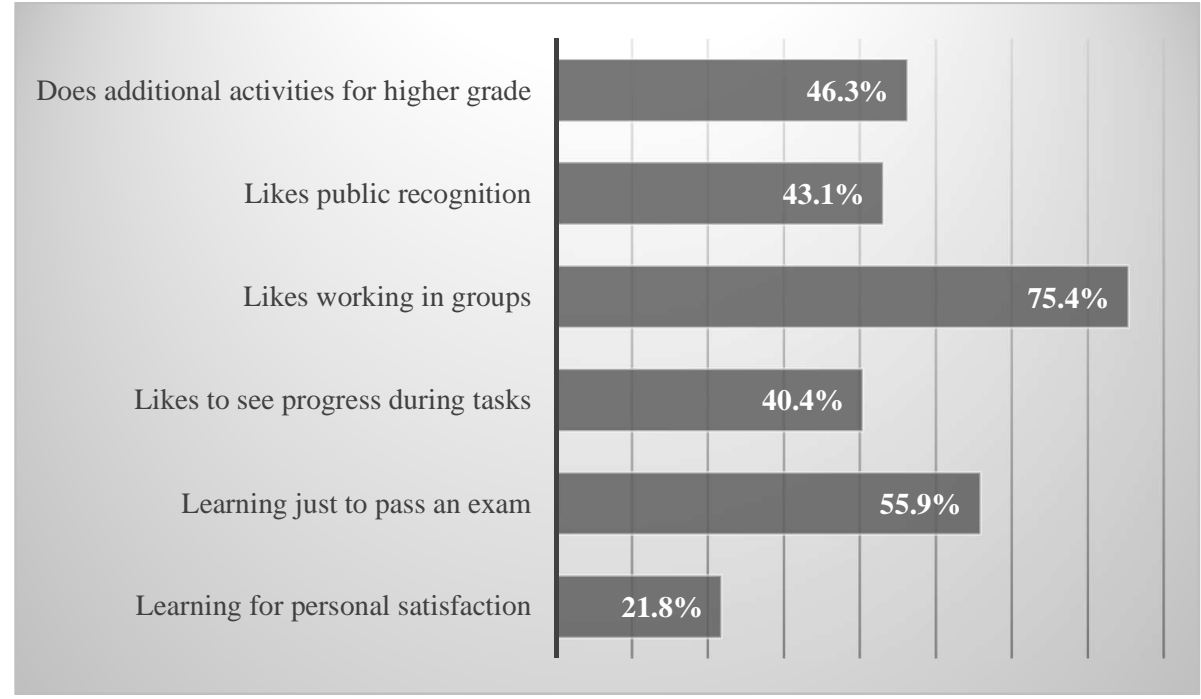

Graph 5. Views towards the learning process

Source: Own source

Graph 5 illustrates students' views towards the learning purpose, as well as their intent and goal. Over three quarters of students like working in groups $(75.4 \%)$, while a large number of students feel that they learn just to pass an exam (55.9\%). Specific answers that are connected to the potential for implementing gamification are doing additional tasks for a higher grade $(46.3 \%)$, 
public recognition (43.1\%), seeing progress during tasks $(40.4 \%)$ and learning for personal satisfaction $(21.8 \%)$. We further researched the reasons behind student participation in class activities, with rewards/points being the main motivator (60.9\%), followed by improving personal skills (42\%) and getting recognition (30.9\%). Students rarely respond to negative motivation (punishment) with $14 \%$ or because of other students $(10 \%)$, while a fairly large percentage of students $(28 \%)$ do not participate in class or do homework activities.

Classroom interested depends on the course itself for some students (39\%). Graph 6 addresses these cases.

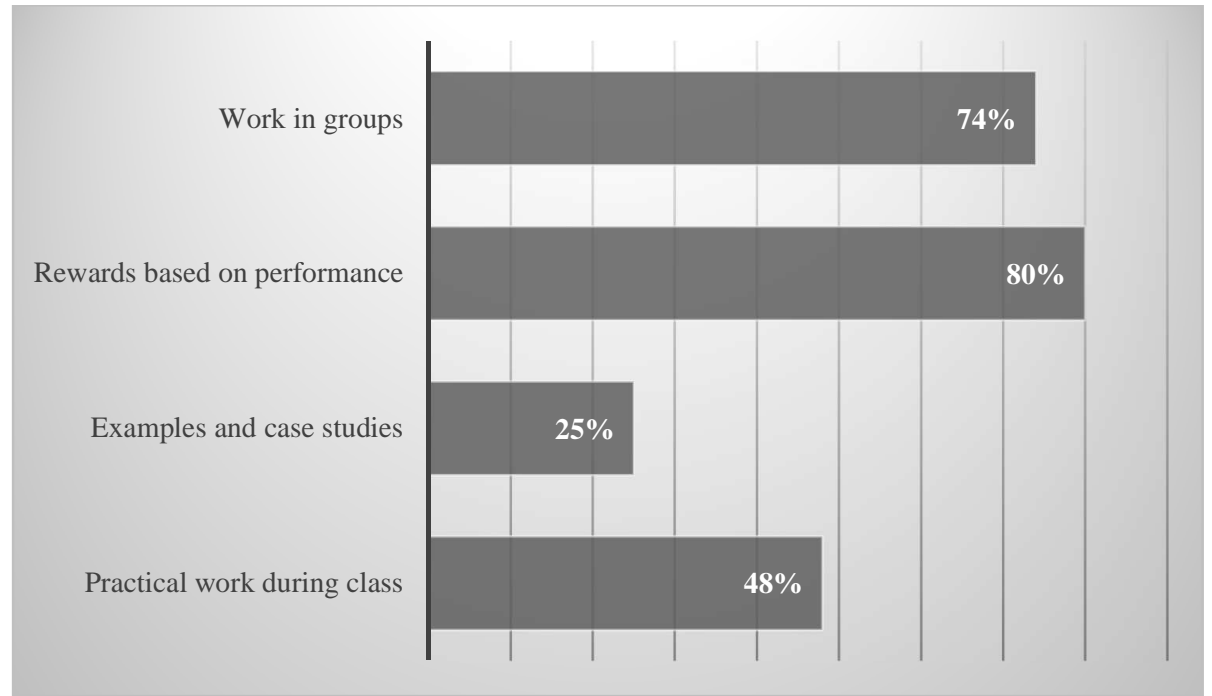

Graph 6. Student motivation for participating more in certain classes

Source: Own source

As shown in graph 6, most of the students that are more invested in certain courses list the reward systems (80\%), work in groups (74\%) and practical work during class (48\%) as the main motivators. This is in line with gamification principles and its' focus on intrinsic motivation. The final two questions were focused specifically on video games. The largest group of students (74\%) plays video games or mobile games (smartphone games) either every day or a few days a week, followed by rarely playing games (14\%) and never playing games (13\%). Most of the students do not know whether introducing elements of video games would make the classroom experience better (66.8\%), while $21.8 \%$ disagree with introducing these types of elements.

\section{CONCLUDING REMARKS}

The primary and secondary research clearly demonstrate the benefits of introducing gamification in the educational process. Attempts have been made to create a fusion between fun and learning in the past through gamification in certain HEIs, although problems and barriers have always been present. The stated principles and steps for implementing gamification in this paper can be followed to minimize potential problems and help teachers to get a better understanding of this concept and its' correct utilization. In short, gamification in Macedonian HEIs offers great potential because of several factors:

- Current and future students are comprised from Generation Z, which has grown up with Internet technologies and smartphone/video games. This generation has already been in touch with certain elements and mechanics from gamification, so they are more susceptible to them. The research show that most of the students are in contact with video 
games or smartphone games on a regular basis (74\%) with only a small percentage stating that they never play video games (13\%).

- Gamification focuses on the intrinsic motivation, which is more difficult to achieve, but also longer lasting than extrinsic motivation. Various case studies show that gamification can yield positive results, from higher attendance, higher engagement rates and ultimately higher average grades for the students.

- Our research shows that most of the students are disinterested (2.9), uninspired (2.4), unfulfilled (2.4) and unmotivated (2.8) during classes. These are all intrinsic motivational factors, which can be engaged with gamification in the learning process. This notion is strengthened by the fact that students would do additional activities to pass an exam (46.3\%), like working in groups (75.4\%) and like public recognition (43.1\%).

- Gamification requires doing tasks for rewards and recognition, and students currently participate in class because of the reward system in place (60.9\%), to improve personal skills $(42 \%)$ and to get recognition (30.9\%). There is also a large percentage of students which do not participate in class activities (28\%), which could be engaged through gamified systems for learning. Students are more interested in classes with rewards based on performance $(80 \%)$ and with practical work during class $(48 \%)$, which is also in line with gamification principles.

- The paper defines the process of designing a gamified system for specific courses by introducing four steps to be followed, specifying the importance of the cycle of interests and progressive cycles and including four different types of dynamics for gamification in the learning process. Tracking these steps is necessary because gamification focuses directly on intrinsic motivators for students, who, although powerful, are also extremely difficult to activate. An improperly designed gamified system could damage the implementation itself, so it is important that teachers pay enough time and attention to it since the initial phase. Implementation can be managed easily via third-party application which can be freely used, such as Superfunner which is discussed in this paper. These types of application already contain finished elements and mechanics which can be used by teachers in their classes in a digital form.

The research can be continued by evaluating the necessary administrative precursors and changes that have to be made to implement gamification in the courses, which can also include changing the syllabus and curriculums, as well as evaluate administrative and teaching staff on their readiness to implement such a system. To fully analyze the potential of gamification in HEIs in the Republic of Macedonia, a case study can be conducted and implement a gamified system in a certain course, through close monitoring and evaluation of the process throughout the semester.

\section{REFERENCES}

Aparicio, A.F. et al., 2012. Analysis and application of gamification. Proceedings of the 13th International Conference on Interacción Persona-Ordenador - INTERACCION '12, pp.1-2.

Benabou R., Tirole J., 2003, Intrinsic and Extrinsic Motivation, Review of Economic Studies, 2003 70, pp. 489-520

Detering S., Dixon D., Khaled R., Nacke L., 2011, From Game Design Elements to Gamefulness: Defining "Gamification", MindTrek'11, September 28-30, 2011, Tampere, Finland

Frischmann N., 2014, Gaming the System: Using Game Elements in Reacting and Non-Reacting Classes, whitepaper available

https://reacting.barnard.edu/sites/default/files/gamification_saturday_handout.pdf (accessed on 10.08.2018)

Hill E., 2015, Level Up: Using Games and Gaming to Improve Teaching and Learning, Adolescent Literacy In Perspective, March/April 2015 
Kiryakova G, Angelova N, Yordanova L. 2014. Gamification in education. Proceedings of 9th International Balkan Education and Science Conference

Kiselicki M., Kirovska Z., Josimovski S., Pulevska L., 2018, The concept of gamification and its use in software companies in the Republic of Macedonia, ECONOMICS AND CULTURE 15(00), 2018

DOI: 10.XXXX/jec-2018-0000

Laskowski M., Badurowicz M., 2014, Gamification in Higher Education: a case study, Human Capital without Borders: Management, Knowledge and Learning for Quality of Life, International Conference, Portoroz, Slovenia

Nicholson, S., 2013. ExploringGamification Techniques for Classroom Management, Games+Learning+Society 9.0, Madison, WI.

Plass, J. L., Homer, B. D., \& Kinzer, C. K. (2015). Foundations of Game-Based Learning.Educational Psychologist,50(4), 258-283. doi:10.1080/00461520.2015.1122533

Ryan R., Deci E., 2000, Intrinsic and Extrinsic Motivations: Classic Definitions and New Directions, Contemporary Educational Psychology 25, 54-67

Sheldon L., 2012. The Multiplayer Classroom: Designing Coursework as a Game. Boston, MA: Cengage Learning.

Singh A., Dangmei J., 2016, Understanding the generation z: the future workforce, South-Asian Journal of Multidisciplinary Studies (SAJMS) ISSN:2349-7858:SJIF:2.246:Volume 3 Issue 3

Stott, A., Neustaedter, C., 2013. Analysis of gamification in education. Surrey, BC, Canada

Symonds, William C., Robert Schwartz, and Ronald F. Ferguson., 2011. Pathways to prosperity: Meeting the challenge of preparing young Americans for the 21st century. Cambridge, MA: Pathways to Prosperity Project, Harvard University Graduate School of Education.

Youssef Adel, B., Thomas, L., \& Ragni, L., 2011, Bridging the Learning Gap in the Market for Higher Education: E-learning and Public Subsidies. Economic analysis, 44(3-4), 1-11.

Van Der Boer, P. 2011, Introduction to Gamification, whitepaper, available at https://www.cdu.edu.au/olt/ltresources/downloads/whitepaper-

introductiontogamification-130726103056-phpapp02.pdf (accessed on 20.03.2018)

\section{Web-sources:}

https://www.wepc.com/news/video-game-statistics/ (accessed on 10.05.2018)

https://www.bigfishgames.com/blog/2017-video-game-trends-and-statistics-whos-playingwhat-and-why/ (accessed on 10.05.2018)

https://www.statista.com/statistics/722259/world-gamers-by-age-and-gender/ (accessed on 11.05.2018)

\begin{tabular}{|l|l|}
\hline Article history: & Received: November 14, 2018 \\
\cline { 2 - 2 } & Accepted: December 9,2018
\end{tabular}

Accepted: December 9, 2018 